PANCREATIC CANCER

\title{
Variants of bcl-2 specific siRNA for silencing antiapoptotic bcl-2 in pancreatic cancer
}

\author{
M Ocker, D Neureiter, M Lueders, S Zopf, M Ganslmayer, E G Hahn, C Herold, D Schuppan
}

Gut 2005;54:1298-1308. doi: 10.1136/gut.2004.056192

See end of article for authors' affiliations

Correspondence to

Dr M Ocker, Department

of Medicine I, Friedrich-

Alexander-University

Erlangen-Nuernberg,

Ulmenweg 18, D-91054

Erlangen, Germany;

Matthias.Ocker@

med 1 .imed.uni-erlangen.

de

Revised version received 29 December 2004

Accepted for publication

16 February 2005
Background and aims: Pancreatic cancer remains a devastating diagnosis with only limited therapeutic options. Specific inhibition of expression of target genes has become possible using small interfering (si) RNAs. We therefore investigated how far siRNA specific for bcl-2 may serve as a therapeutic option for pancreatic cancer in vitro and in vivo.

Methods: siRNAs targeting two different regions in the bcl-2 gene were transfected to YAP C and DAN G pancreatic carcinoma cells and human foreskin fibroblasts. Permutations were generated by changing 3' and $5^{\prime}$ overhangs and varying the length of the paired RNA duplex. Transfection efficacy was determined using FITC labelled siRNAs and fluorescence microscopy. Cell survival and apoptosis were quantified at 24-120 hours. Pancreatic cancer xenografts in male nude mice were treated intraperitoneally with siRNAs daily for 24 days. siRNA pharmacokinetics in vivo were assessed using radioactively labelled siRNAs. Total protein and RNA were extracted for western Blot analysis and quantitative polymerase chain reaction.

Results and conclusions: bcl-2 specific siRNAs specifically inhibited expression of the target gene in vitro and in vivo. Antiproliferative and proapoptotic effects were observed in tumour cells but not in fibroblasts or non-malignant tissues. siRNA permutations and diverse overhangs influenced gene silencing efficacy. siRNA was quickly distributed to all organs and excreted via the kidney and liver. bcl-2 specific siRNA is a promising adjunctive treatment for pancreatic carcinoma.
$\mathrm{P}$ ancreatic cancer is one of the most common causes of cancer related deaths in Western countries and represents approximately $10 \%$ of all gastrointestinal malignancies. ${ }^{1}$ Ductal adenocarcinoma is responsible for $90 \%$ of all cases and is often diagnosed at an advanced stage, with a median survival time of less than six months and 12 month and five year survival rates of only $10 \%$ and less than $3 \%$, respectively. Hence pancreatic cancer has the poorest prognosis of many neoplasms. ${ }^{23}$ Only $10-14 \%$ of patients are eligible for curative surgery which prolongs median survival to 10-20 months. ${ }^{45}$ Various adjuvant, neoadjuvant, locoregional, or radiochemotherapy strategies could not significantly improve overall survival, and still remain palliative. ${ }^{45}$

Several genetic risk factors have been identified to date. ${ }^{6}$ Among these, activating point mutations in codon 12 of the $\mathrm{K}$-ras proto-oncogene can be found in up to $90 \%$ of tumour specimens. ${ }^{78}$ Other factors include mutations of $\mathrm{pl} 6^{\text {INK4 }}$, the deleted in colon cancer gene (DCC), p53, and related cell cycle control genes. ${ }^{9}{ }^{10}$ Furthermore, the antiapoptotic gene bcl-2 is highly expressed in most pancreatic cancers. ${ }^{11}{ }^{12}$ The family of bcl-2 homologues consists of proapoptotic members such as bax, bad, bid, or bim, and anti-apoptotic members such as bcl-2 or bcl- $\mathrm{x}_{\mathrm{L}}$ which regulate central pathways in cell survival, apoptosis induction, and resistance to chemotherapy. ${ }^{13-16}$ While antiapoptotic bcl-2 stabilises mitochondrial membranes, proapoptotic bax or bak disturb the integrity of these membranes after oligomerisation, leading to release of proapoptotic cytochrome $c$ from the mitochondrial intermembrane space which then activates procaspase 9, triggers activation of other effector caspases, and causes the execution of apoptosis. ${ }^{16}$ Several studies have shown that inhibiting expression of antiapoptotic bcl-2 inhibits growth and induces apoptosis, frequently enhancing the effects of conventional chemotherapy in various malignancies-for example, lymphoma, ${ }^{17}$ leukaemia, ${ }^{18}$ breast cancer, ${ }^{19}$ melanoma, ${ }^{20}$ or gastric cancer. ${ }^{21}$ Suppression of expression of antiapoptotic bcl-2 has so far been investigated using antisense oligonucleotides. ${ }^{22}$ However, preclinical and clinical studies did not demonstrate convincing antitumour efficacy due to unspecific effects (for example, complement activation, thrombocytopenia, cytokine release), hepatotoxicity, and the need to introduce chemical modifications (for example, locked nucleic acids) to stabilise these molecules. ${ }^{22-24}$

We therefore exploited the recently discovered mechanism of specific suppression of a target gene by short double stranded (ds) oligoribonucleotides utilising the RNA interference (RNAi) pathway. RNAi is a highly conserved pathway of cleaving dsRNA (for example, after viral infection) by generating short interfering RNA (siRNA) molecules, duplexes of 21-23 nt in length, which use the RNase IIIlike enzyme DICER. ${ }^{25-28}$ Intracellularly, DICER generated or chemically synthesised siRNAs are separated into single strands by an ATP dependent helicase and become incorporated into the RNA induced silencing complex (RISC). RISC binds the cognate endogenous mRNA and cleaves the target molecule if the siRNA derived antisense strand is incorporated. ${ }^{29-31}$ siRNAs and RNAi have been used to silence different target genes in vitro and in model organisms in vivo. $^{32-34}$ As a therapeutic tool, siRNAs have been used to suppress the replication of several viruses (for example, hepatitis $\mathrm{C}$ virus ${ }^{35}$ or human immunodeficiency virus), ${ }^{36}$ and expression of inflammatory genes or oncogenes such as bcrabl, for example. ${ }^{37}$

We therefore studied the pharmacokinetics of parenterally administered siRNA, and determined if, and to what extent, a tumour gene specific siRNA targeted to bcl-2 could contribute

Abbreviations: siRNA, short interfering RNA; RNAi, RNA interference; ds, double stranded; RISC, RNA induced silencing complex; FCS, fetal calf serum; PBS, phosphate buffered saline; FACS, fluorescence activated cell sorter; FITC, fluorescein isothiocyanate; RT-PCR, reverse transcription-polymerase chain reaction 


\begin{tabular}{|c|c|c|}
\hline siRNA & Sequence & Comment \\
\hline Bcll & $\begin{array}{l}\text { 5'-CAGGACCUCGCCGCUGCAGACC-3' } \\
\text { 3'-CGGUCCUGGAGCGGCGACGUCUGG-5' }^{\prime} \text { 'CG }\end{array}$ & Starting position: 1659 \\
\hline $\mathrm{Bcl} 3$ & $\begin{array}{l}\text { 5'-GCCUUUGUGGAACUGUACGGCC-3' } \\
\text { 3'-UACGGAAACACCUUGACAUGCCGG-5' }\end{array}$ & Starting position: 2047 \\
\hline Bcl5 & $\begin{array}{l}\text { 5'-CAGGACCUCGCCGCUGCAGAC-3' } \\
3^{\prime} \text {-CGGUCCUGGAGCGGCGACGUCUG-5' }\end{array}$ & Starting position: 1659 \\
\hline Bcl8 & $\begin{array}{l}\text { 5'-GCCUUUGUGGAACUGUACGGC-3' } \\
\text { 3'-UACGGAAACACCUUGACAUGCCG-5' }\end{array}$ & Starting position: 2047 \\
\hline Bcl11 & $\begin{array}{l}\text { 5'-UGUGGAUGACUGAGUACCUGA-3' } \\
\text { 3'-GGACACCUACUGACUCAUGGACU-5' }\end{array}$ & Starting position: 1982 \\
\hline Control1 & $\begin{array}{l}5^{\prime} \text {-GAUGAGGAUCGUUUCGCAUGA-3' } \\
\text { 3'-UCCUACUCCUAGCAAAGCGUACU-5' }\end{array}$ & Eukaryotic kanamycin resistance protein \\
\hline Control2 & $\begin{array}{l}5^{\prime} \text {-CCACAUGAAGCAGCACGACUU-3' } \\
3^{\prime} \text {-CUGGUGUACUUCGUCGUGCUGAA-5' }\end{array}$ & EGFP expression vector \\
\hline Control3 & $\begin{array}{l}\text { 5'-ACGGCUAGCUGUGAAAGGUCC-3' } \\
\text { 3'-UCUGCCGAUCGACACUUUCCAGG-5' }\end{array}$ & 3' UTR of hepatitis C virus \\
\hline
\end{tabular}

to the treatment of pancreatic cancer. We also investigated if structural variations in bcl-2-siRNA could influence RNAi efficacy in vitro and in vivo.

\section{MATERIAL AND METHODS \\ Cell culture}

YAP C and DAN G pancreatic adenocarcinoma cells were cultured on six well tissue culture plates (Becton Dickinson, Mannheim, Germany) in RPMI-1640 medium (Biochrom, Berlin, Germany) containing 10\% fetal calf serum (FCS, Biochrom), penicillin (107 U/l), and streptomycin $(10 \mathrm{mg} / \mathrm{l})$ at $37^{\circ} \mathrm{C}$ with $5 \% \mathrm{CO}_{2}$. Human foreskin fibroblasts served as non-malignant controls and were cultured in Dulbecco's modified Eagle's medium (Biochrom) with the same supplements. All cell lines were obtained from the German Collection of Microorganisms and Cell Cultures (DSMZ, Braunschweig, Germany).

\section{Transfection of siRNA}

siRNA was provided by Ribopharma AG (Kulmbach, Germany) or purchased from Qiagen (Hilden, Germany). Sequences of the five bcl-2 specific and three control siRNAs used are given in table 1 . bcl-2 specific sequences were numbered consecutively.

Transfections were performed at approximately 70\% confluency in six well plates using oligofectamine (Invitrogen, Carlsbad, California, USA) according to the manufacturer's instructions. Briefly, $0.25 \times 10^{6}$ cells were seeded in complete growth medium the day before transfection. For each transfection reaction, siRNA-oligofectamine complexes were prepared by mixing oligonucleotides with oligofectamine diluted 1:5 (v/v) with medium directly before addition to the cells. Final concentrations of the siRNA were between 1 and $100 \mathrm{nM}$. Transfections were performed in $1 \mathrm{ml}$ of serum free medium for four hours. Thereafter, $0.5 \mathrm{ml}$ of medium containing 30\% FCS $(\mathrm{v} / \mathrm{v})$ was added to achieve complete growth conditions ( $10 \%$ FCS). In each experiment, untreated controls and mock transfected cells, receiving only oligofectamine without siRNA, were included. Cells were assayed 24 to 120 hours after transfection.

\section{Flow cytometric analysis of apoptosis and bcl-2 protein levels}

For quantification of apoptosis, culture supernatants were collected and cells washed twice with phosphate buffered saline (PBS), trypsinised, and lysed in a hypotonic solution containing $0.1 \%$ sodium citrate, $0.1 \%$ Triton $X-100$, and
$50 \mu \mathrm{g} / \mathrm{ml}$ propidium iodide (Sigma, Deisenhofen, Germany). Analysis of labelled nuclei was performed on a FACSCalibur fluorescence activated cell sorter (FACS) using CELLQuest software (both from Becton Dickinson). The percentage of apoptotic cells was determined by measuring the fraction of nuclei with a subdiploid DNA content.

To assess bcl-2 protein levels by flow cytometry, cells were transfected and harvested as described. Fixation and membrane permeabilisation were performed with Fix and Perm, as recommended by the manufacturer (Caltag Laboratories GmbH, Hamburg, Germany). A FITC conjugated bcl-2 specific antibody ( $10 \mu \mathrm{l}$ F7053; Dako, Glostrup, Denmark) was added for 15 minutes at room temperature in the dark. Samples were washed with PBS, centrifuged at $300 \mathrm{~g}$, resuspended in PBS, and kept on ice in the dark until FACS analysis with fluorescence detector FLl-H. Ten thousand events were collected for each sample analysed.

\section{Determination of cell viability}

Cell viability was assessed using the trypan blue exclusion test. Cells were harvested after the incubation period and stained with trypan blue (Biochrom). The number of unstained (intact) cells was counted in a Neubauer chamber and expressed as relative cell numbers compared with untreated controls $(=100 \%)$.

\section{Analysis of $\Delta \Psi_{m}$}

Mitochondrial injury was assessed by JC-1 staining (MoBiTec, Goettingen, Germany). Cells were adjusted to a density of $0.2 \times 10^{6} / \mathrm{ml}$, trypsinised, washed in PBS, resuspended in $1 \mathrm{ml}$ of medium, stained with $5 \mu \mathrm{g} / \mathrm{ml} \mathrm{JC-1}$ for 15 minutes at $37^{\circ} \mathrm{C}$ with $5 \% \mathrm{CO}_{2}$ in the dark, then washed twice in PBS and resuspended in $0.5 \mathrm{ml}$ PBS. Analysis was performed by FACS scan, and mitochondrial function was assessed as JC-1 green (uncoupled mitochondria, detector FL-1, $537 \mathrm{~nm}$ ) or red (intact mitochondria, detector FL-2, $597 \mathrm{~nm}$ ) fluorescence, as described previously. ${ }^{38}$

\section{Fluorescence microscopy of FITC labelled siRNA}

siRNA was labelled with fluorescein isothiocyanate (FITCsiRNA, obtained from Ribopharma, Kulmbach, Germany or from the siRNA Starter Kit, Qiagen, Germany) and transfected to cells seeded on ChamberSlides, as described above. Twenty four hours after transfection, cells were washed in $1 \times$ PBS (Biochrom) and fixed for 30 minutes in ice cold methanol at $-20^{\circ} \mathrm{C}$. After an additional washing in PBS, nuclei were counterstained with $1 \mu \mathrm{g} / \mathrm{ml}$ propidium iodide 
Table 2 Primers and probes for quantitative real time polymerase chain reaction

\begin{tabular}{llll}
\hline Target gene & $\mathbf{5}^{\prime}$-primer & Probe & $\mathbf{3}^{\prime}$-primer \\
\hline Bax & GTCCACCAAGAAGCTGAGCG & GAGCTGCAGAGGATGATTGCCGCC & TCGGAAAAAGACCTCTCGGG \\
Bcl-2 & CCTGGTGGACAACATCGCC & AACGGAGGCTGGGATGCCTTTGTG & AATCAAACAGAGGCCGCATGC \\
$\beta_{2}$-microglobulin & TGACTTGTCACAGCCCAAGATA & TGATGCTGCTACATGTCTCGATCCCA & AATCCAAATGCGGCATCTTC \\
\hline
\end{tabular}

Probes were labelled with the reporter dye FAM at the $5^{\prime}$-end and with the quencher molecule TAMRA at the $3^{\prime}$-end. $5^{\prime}$ - and $3^{\prime}$-primers were designed to span exon-intron boundaries to minimise the amplification of genomic DNA.

(Sigma) for 20 minutes at room temperature in the dark. Slides were covered with fluorescent mounting medium (Dako). Fluorescence microscopy was performed using a Zeiss Axioplan microscope (Carl Zeiss, Göttingen, Germany) at $490 \mathrm{~nm}$ excitation (FITC-siRNA, $525 \mathrm{~nm}$ emission) and $536 \mathrm{~nm}$ excitation (propidium iodide, $617 \mathrm{~nm}$ emission), respectively. Digital image analysis was performed using OpenLab software (Improvision, Heidelberg, Germany).

\section{Preparation of RNA, CDNA, and quantitative real time PCR}

Total RNA was prepared from $0.25 \times 10^{6}$ untreated controls or transfected cells, 24-120 hours after transfection using peqGOLD RNA Pure (Peqlab, Erlangen, Germany) according to the manufacturer's instructions and subsequent phenol-chloroform extraction. RNA integrity was checked electrophoretically and quantified photometrically. The concentration of total RNA was adjusted to $0.1 \mu \mathrm{g} / \mu \mathrm{l}$ in RNAse free water.

For reverse transcription (RT), l $\mu \mathrm{l}$ of a primer mix containing $100 \mathrm{pmol} / \mu \mathrm{l}$ oligo $(\mathrm{dT})_{15}$ primer and $100 \mathrm{pmol} / \mu \mathrm{l}$ random hexamer primer $\left(5^{\prime}-\mathrm{NNN} \mathrm{NNN}-3^{\prime}\right)$, both from Promega (Mannheim, Germany), were incubated with $1 \mu \mathrm{g}$ RNA and denatured for 10 minutes at $70^{\circ} \mathrm{C}$. An RT reaction mix consisting of $5 \times$ RT reaction buffer (Invitrogen, Karlsruhe, Germany), 0.1 M DTT (Invitrogen), and a dNTP mix with $10 \mathrm{mM}$ of each dNTP was added together with $40 \mathrm{U}$ RNAsin RNAse inhibitor (Promega) and 100 U Superscript II reverse transcriptase (Invitrogen) and placed on ice for two minutes. Total reaction volume was adjusted to $20 \mu \mathrm{l}$ with RNAse free water and incubated for 10 minutes at $25^{\circ} \mathrm{C}$ and cDNA synthesised for one hour at $42^{\circ} \mathrm{C}$. The reaction was stopped by 15 minutes heat inactivation at $70^{\circ} \mathrm{C}$ and cDNA stored at $-20^{\circ} \mathrm{C}$ until use.

Relative transcript levels were quantified by real time RTpolymerase chain reaction (PCR). Sense and antisense primers (each at $0.5 \mu \mathrm{M}$ ) and $0.125 \mu \mathrm{M} 5^{\prime}$-phosphorylated probe, labelled with the reporter dye FAM (carboxyfluorescein) at the $5^{\prime}$-end and with the quencher molecule TAMRA (carboxy-tetramethylrhodamine) at the 3'-end, were synthesised at MWG Biotech (Ebersberg, Germany). PCR primers and probes (table 2) were designed to span exonintron boundaries, reducing the risk of detecting genomic DNA. Real time RT-PCR was performed with $1.5 \mu \mathrm{l}$ of template cDNA on a LightCycler system (Roche, Mannheim, Germany) in a total reaction volume of $15 \mu \mathrm{l}$, including TaqDNA polymerase, dNTP-mix, reaction buffer, and $3 \mathrm{mM} \mathrm{MgCl}_{2}$, provided by the LightCycler FastStart DNA Master Hybridisation Probes Kit (Roche Molecular Biochemicals, Mannheim, Germany) according to the manufacturer's instructions. For amplification of bax and bcl-2, PCR was performed with a precycling step at $95^{\circ} \mathrm{C}$ for 10 minutes for activation of TaqDNA polymerase, followed by 55 cycles with a denaturation step at $95^{\circ} \mathrm{C}$ of less than one second, 15 seconds annealing at $55^{\circ} \mathrm{C}$, and 15 seconds extension at $65^{\circ} \mathrm{C}$. $\beta_{2}$-Microglobulin was amplified as an internal standard using a precycling step at $95^{\circ} \mathrm{C}$ for 10 minutes, 45 cycles of less than one second at $95^{\circ} \mathrm{C}$, 15 seconds at $53^{\circ} \mathrm{C}$, and 25 seconds at $63^{\circ} \mathrm{C}$. A cooling step to $40^{\circ} \mathrm{C}$ finalised all amplifications. For every measured transcript, a $1: 2$ to $1: 32$ dilution series of one sample was used as standard. Data were analysed with the LightCycler software using the proportional second derivative maximum option. To normalise for differences in RNA amounts and variable efficacy of the reverse transcription reactions, results for bax and bcl-2 were normalised to $\beta_{2}$-microglobulin levels. All samples were analysed in duplicate.

\section{Xenograft model}

Human pancreatic carcinomas established from Panc-1 cells were transplanted subcutaneously to 4-6 week old nude mice (Harlan Winkelmann GmbH, Germany). ${ }^{39}$ Animals were housed in a light and temperature controlled environment and provided with food and water ad libitum. Treatment was started when tumours reached $7 \mathrm{~mm}$ in diameter. Animals received intraperitoneal injections of $200 \mu \mathrm{g} / \mathrm{kg}$ siRNA dissolved in $120 \mu \mathrm{l}$ RNAse free physiological NaCl. Control mice were treated with $\mathrm{NaCl}$ alone. Tumour size was determined daily by measurement with a calliper square. After 24 days, animals were sacrificed by cervical dislocation and specimens of tumour, liver, lung, kidney, spleen, and bone marrow were either fixed in $10 \%$ phosphate buffered formalin or snap frozen in liquid nitrogen for protein extraction, as described below. Ethics approval was obtained for all experiments (621-2531.31-20/01, Government of Lower Franconia, Würzburg, Germany).

\section{Semiquantification of proteins involved in apoptosis}

Snap frozen tumour specimens were lysed by adding $2 \times$ sample buffer (2 mM N-ethylmaleimide, $2 \mathrm{mM}$ phenylmethyl-sulfonylfluoride, $4 \%$ sodium dodecyl sulfate, $4 \%$ dithiothreitol, $20 \%$ glycerol, $0.01 \%$ bromophenol blue, $2 \mathrm{M}$ urea, $0.01 \mathrm{M}$ sodium ethylenediaminetetra-acetic acid (NaEDTA), $0.15 \mathrm{M}$ Tris-HCl). DNA was sheared by pipetting up and down for three minutes at room temperature. Samples were boiled at $95^{\circ} \mathrm{C}$ for 15 minutes, centrifuged at $13000 \mathrm{rpm}$ for 10 minutes, and then subjected to $14 \%$ sodium dodecyl sulphate-polyacrylamide gel electrophoresis (Invitrogen). After blocking overnight at room temperature in a buffer containing PBS, $0.1 \%$ Tween 20 , and $4 \%$ low fat milk powder, nitrocellulose membranes were incubated for 90 minutes either with polyclonal rabbit antihuman Bcl-2 (1:400, sc-783) or polyclonal rabbit antihuman Bax (1:500, sc-493; both Santa Cruz Biotechnology, Santa Cruz, California, USA). Membranes were washed three times for 10 minutes in a buffer containing PBS, $0.1 \%$ Tween 20, and $4 \%$ low fat milk powder, and incubated with an antirabbit IgG coupled to peroxidase (1:1000; Sigma) for one hour at room temperature. Reactive bands were detected with the ECL chemiluminescence reagent (Amersham Pharmacia Biotech, Freiburg, Germany) and analysed using GelScan 5 software (BioSciTec, Frankfurt, Germany). Signals were standardised to $\beta$-actin (1:5000; Sigma) content.

\section{Distribution of radioactive labelled siRNA in vivo}

siRNA probe bcl5 was labelled radioactively with ${ }^{33} \alpha$-UTP and applied as a single bolus in physiological saline by tail vein injection into non-tumour bearing male nude mice at a 


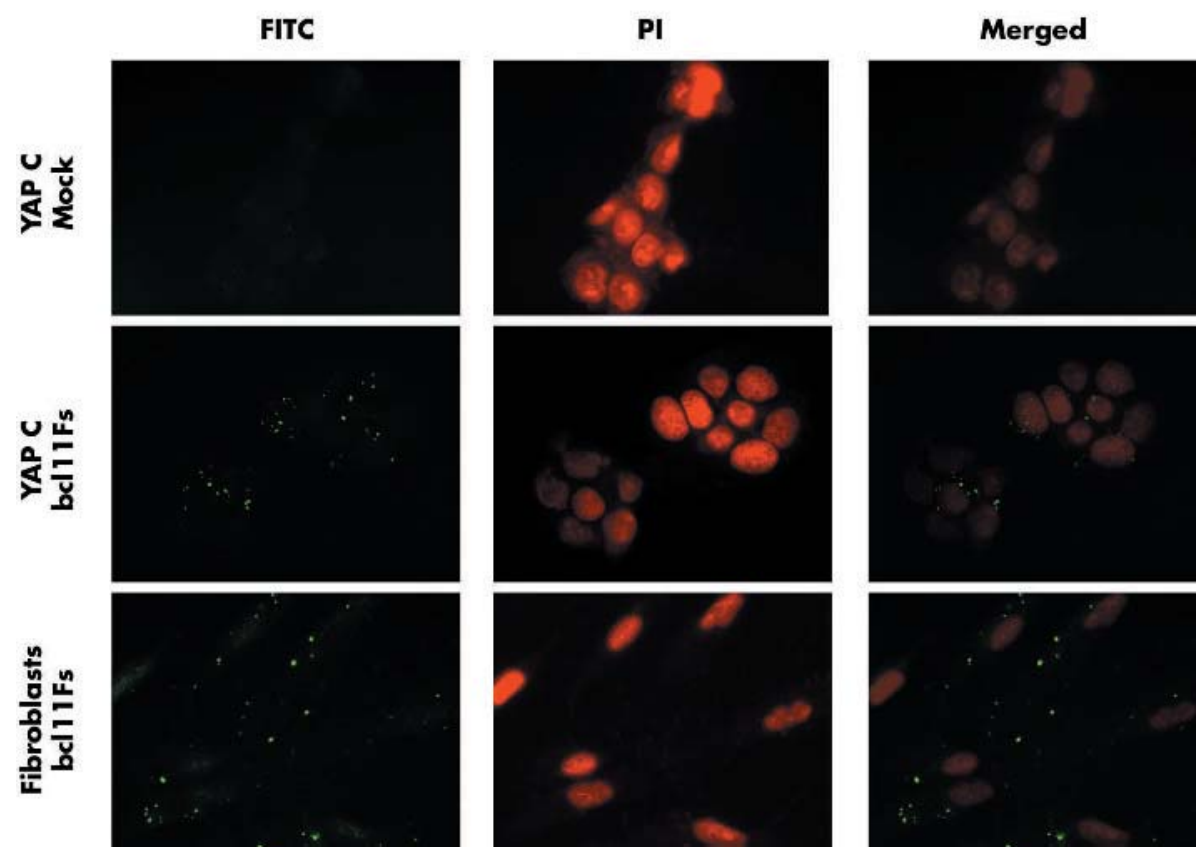

Figure 1 Short interfering RNA (siRNA) transfection efficacy, as assessed by fluorescence microscopy. Slides were analysed for fluorescein isothiocyanate (FITC) and propidium iodide (PI) fluorescence. Digital images were acquired and merged with OpenLab software for each channel independently. PI stained nuclei were detectable in all analysed slides, while FITC signals were not present in untreated controls (not shown) or mock transfected cells (top row). Cells transfected with $100 \mathrm{nM}$ FITC-siRNA exhibited distinct intracellular and perinuclear staining (both fibroblasts or YAP C cells). No qualitative difference was detectable between siRNA labelled on the sense or antisense strand (not shown).

concentration of $1 \mathrm{mg} / \mathrm{kg}$, corresponding to $360.000 \mathrm{cpm} / \mu \mathrm{l}$. Pure ${ }^{33} \alpha$-UTP $(360000 \mathrm{cpm} / \mu \mathrm{l}$ ) dissolved in physiological saline was used as a control. Three animals per group were kept in metabolic cages to collect faeces and urine. Five minutes to 24 hours after injection, animals were sacrificed by heart puncture and total blood samples collected and fixed with RNAlater (Qiagen, Hilden, Germany). Whole bodies were fixed in formalin, as described above, and cut in sagittal and paramedian plains and $5 \mu \mathrm{m}$ serial sections. Sections were stained with haematoxylin and eosin and analysed for
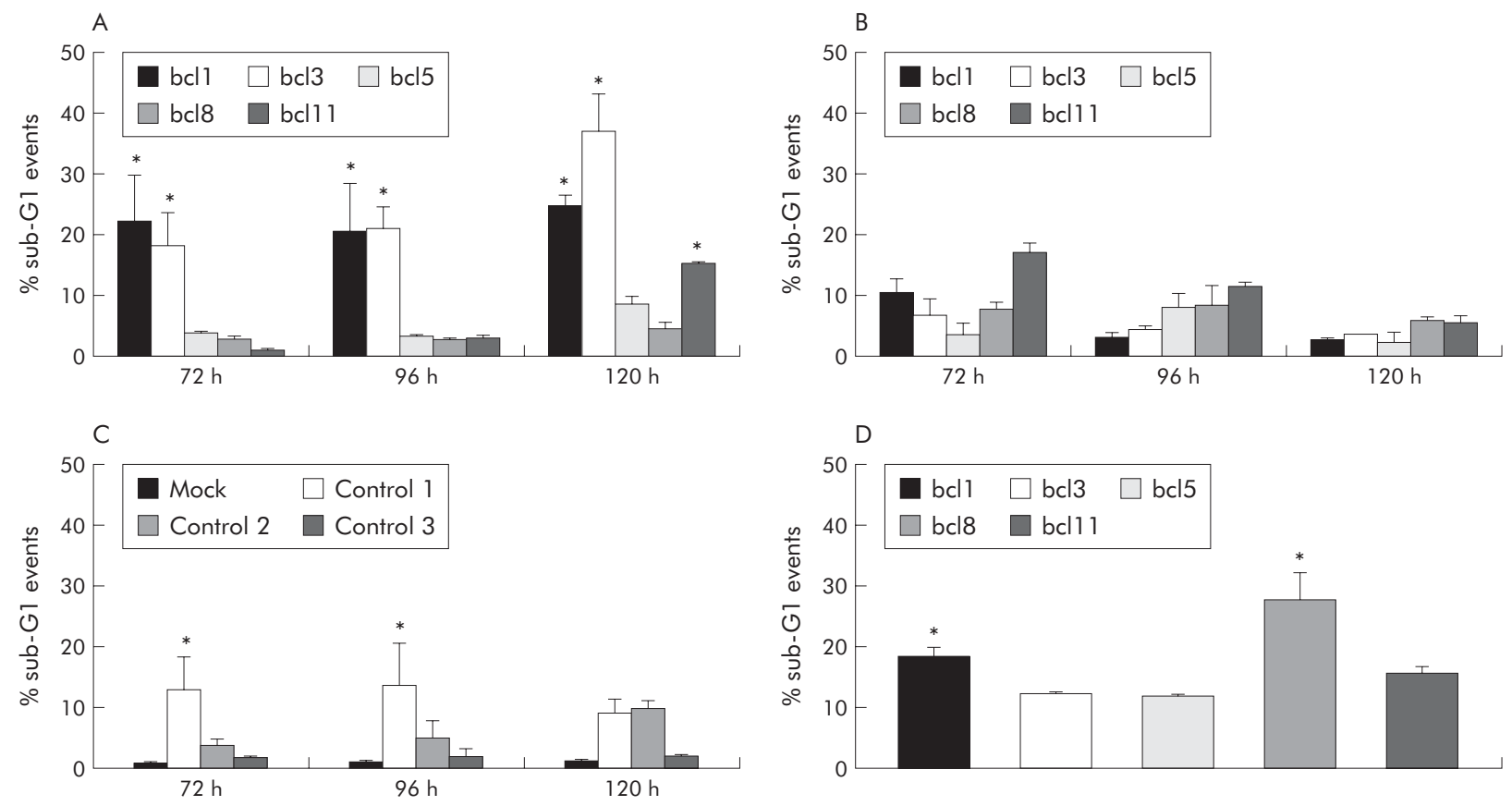

Figure 2 Induction of apoptosis by bcl-2 specific short interfering RNAs (siRNAs) in pancreatic cancer cells but not in non-transformed foreskin fibroblasts. Shown are apoptosis rates measured as subdiploid events in flow cytometry by propidium iodide staining after transfection with $10 \mathrm{nM}$ bcl-2 specific (A) or non-silencing (C) siRNA in YAP C pancreatic carcinoma cells 72, 96, and 120 hours after transfection. Results for bcl-2 specific siRNAs in foreskin fibroblasts are shown in (B). (D) Results of apoptosis induction by $10 \mathrm{nM}$ bcl-2 specific siRNAs in DAN G pancreatic carcinoma cells 120 hours after transfection. Values are means (SEM) of three independent experiments. ${ }^{*} p<0.05$. 

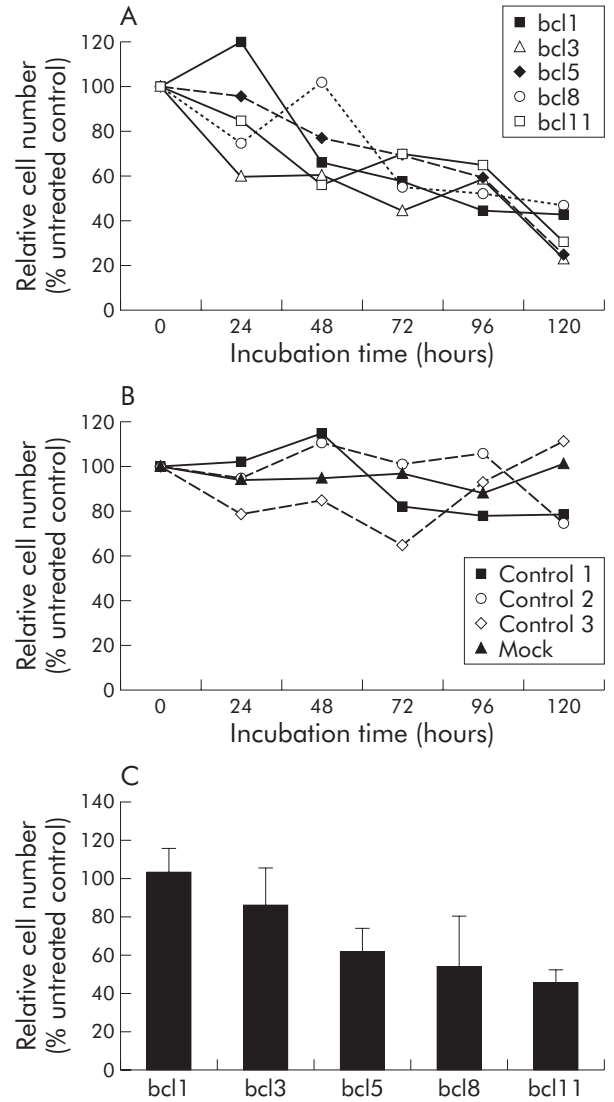

Figure 3 Relative cell number of YAP C cells, 24-120 hours after transfection with different short interfering RNAs (siRNAs). Absolute cell numbers of three independent experiments were determined by trypan blue staining in a Neubauer chamber. Average cell number of untreated controls was set at $100 \%$ and relative numbers of samples calculated accordingly. (A) Reduction of relative cell number after transfection of $10 \mathrm{nM}$ bcl-2 specific siRNAs. (B) Stable cell viability after mock transfection or transfection of control siRNAs. (C) Reduced number of viable DAN G cells 120 hours after transfection with $10 \mathrm{nM} \mathrm{bcl}-2$ specific siRNA.

24 hours in a Fuji FLA-3000 phospho and fluorescence imager (Raytest GmbH, Straubenhardt, Germany).

\section{Immunohistochemistry}

Tumour tissue was fixed with phosphate buffered 10\% formalin and embedded in paraffin. Sections $(5 \mu \mathrm{m})$ were cut and stored at room temperature until use. Routine histology (haematoxylin-eosin staining) was performed in order to evaluate basic histomorphological features of the specimens and to determine toxic effects on organs, especially the liver, spleen, kidney, and haematopoietic system. For immunohistochemistry, sections were dewaxed, rehydrated, and processed by microwave heating in citrate buffer ( $\mathrm{pH}$ 6.0), as described previously. ${ }^{40}$ Specimens were incubated with monoclonal primary antibodies (anti-Ki-67, 1:50; anti-bcl-2, 1:100; Dako) overnight at $4^{\circ} \mathrm{C}$ and visualised using streptavidin-biotin complex (Biogenex, San Ramon, California, USA) coupled to alkaline phosphatase and developed using 3-hydroxy-2-naphtylacide-2,4-dimethylanilide as substrate. Nuclei were counterstained with haematoxylin. Replacement of primary antibodies by non-immune mouse or rabbit serum (BioGenex) or Tris buffered saline ( $\mathrm{pH}$ 7.2) served as negative controls. Slides were digitised and analysed with the Ce2001 Cell Explorer software (BioSciTec, Frankfurt Germany). Semiquantification was performed for
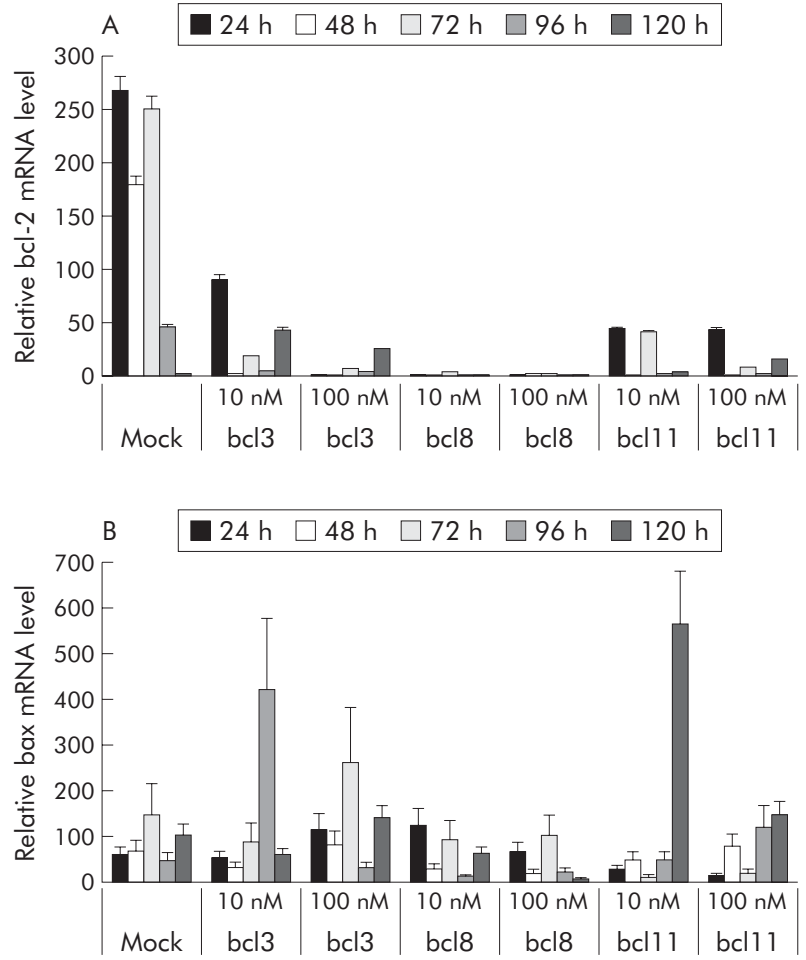

Figure 4 bcl-2 mRNA was rapidly downregulated by specific short interfering RNAs (siRNAs) in pancreatic cancer cells. Shown are mean values of two independent transfections of YAP C cells and two independent quantitative polymerase chain reaction amplifications of each transfection. Expression of bcl-2 (A) and bax (B) was normalised to $\beta_{2}$-microglobulin mRNA levels. Results are expressed relative to normalised $\beta_{2}$-microglobulin mRNA content of untreated controls $(=100)$.

four independent high power fields in each slide, using electronic filtering for respective signals.

\section{RESULTS}

\section{siRNAs are effectively delivered into pancreatic cancer cells in vitro}

To optimise the transfection protocol, siRNA labelled with FITC at either the $5^{\prime}$-end of the sense strand or the $5^{\prime}$-end of the antisense strand was used. Compared with untransfected or mock transfected cells without FITC signals, distinct intracellular fluorescence staining was observed in cells transfected with FITC labelled siRNA. These signals showed intracytoplasmic and perinuclear localisation, in accordance with the current notion of RNAi occurring as a posttranscriptional process. No qualitative difference was observed between sense or antisense labelled siRNA molecules. As this assay was used to confirm cellular uptake of siRNAs, cells were fixed 24 hours after transfection. At this early time point, no morphological signs of cellular apoptosis were found, indicating low toxicity of the transfection reagent used. The transfection protocol used was optimised for transfecting YAP C cells and human foreskin fibroblasts at comparable efficacy (fig 1).

\section{Bcl-2 specific siRNAs selectively induce apoptosis in pancreatic cancer cells}

At $10 \mathrm{nM}$, siRNAs bcll, bcl3, and bclll induced significant levels of apoptosis in YAP C, reaching a maximum of $25.0 \%$, $37.1 \%$, and $15.4 \%$ after 120 hours, respectively (fig $2 \mathrm{~A}$ ), which did not increase further using $100 \mathrm{nM}$ siRNA. Apoptosis remained low after transfection of bcl5 and bcl8, 

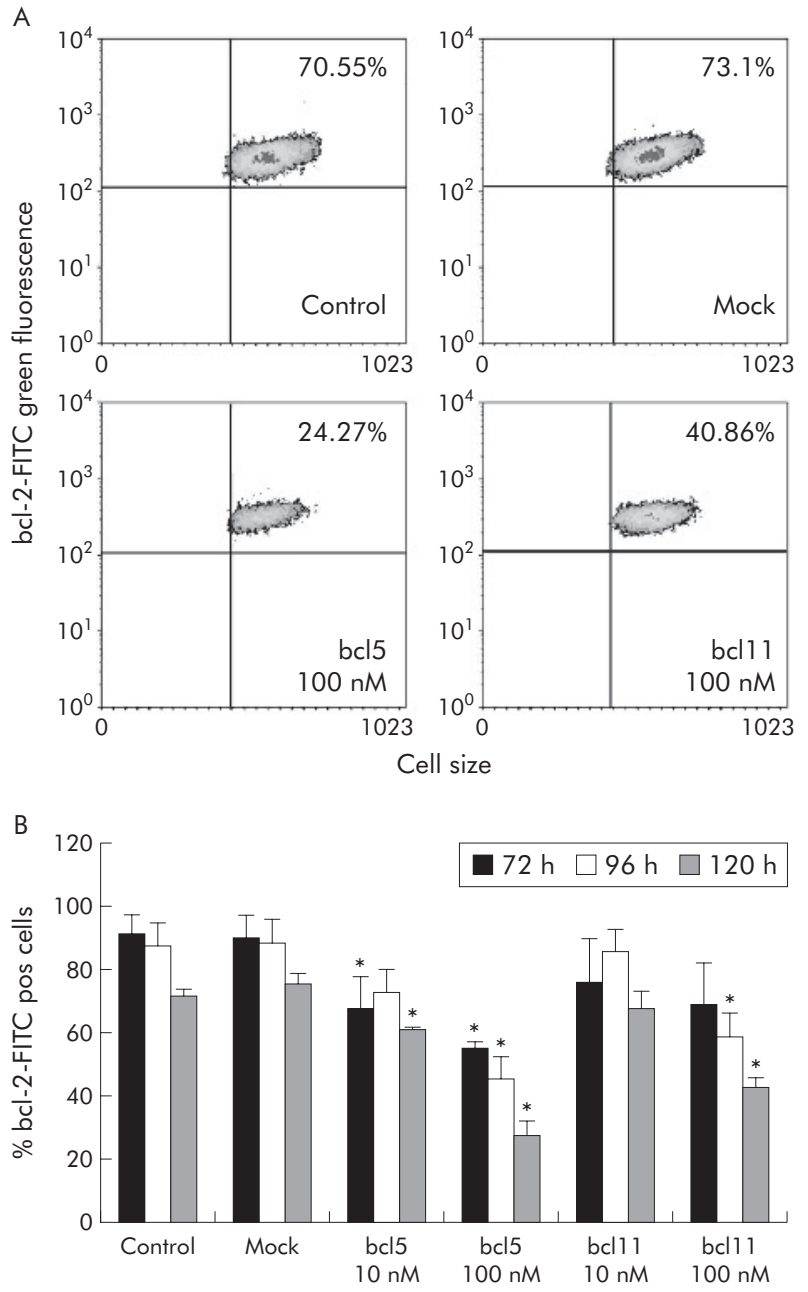

Figure 5 Reduction of bcl-2 protein levels in viable YAP C cells. (A) Protein expression of bcl-2 was determined by flow cytometry after transfection with bcl5 or bcl 1 and staining with a monoclonal fluorescein isothiocyanate (FITC) labelled anti-bcl-2 antibody. Viable cells were gated by cell size (forward scatter) and fluorescence was analysed with fluorescence light detector FL1-H $(530 \mathrm{~nm})$. (B) Quadrant analysis revealed a time and dose dependent downregulation of bcl-2 protein positive cells 72-120 hours after transfection of corresponding short interfering RNAs (siRNAs). Mock transfected or untreated control cells showed no changes in bcl- 2 protein expression. ${ }^{*} p<0.05$ versus mock transfected cells. Shown are means (SEM) of three independent experiments.

reaching only $8.6 \%$ and $4.5 \%$, respectively, after 120 hours. No effect on cell death was observed in cells transfected with $1 \mathrm{nM}$ of any siRNA (data not shown), and even the most effective bcl-2 specific siRNA, bcl3, could not induce apoptosis in non-transformed skin fibroblasts (fig 2B). Furthermore, control siRNAs with no corresponding endogenous target sequences also failed to activate cellular death signalling pathways in pancreatic cancer cells (fig 2C) or fibroblasts (not shown), except for control siRNA l which induced some apoptosis in tumour cells. After 120 hours, apoptosis rates of untreated or mock transfected YAP C cells or fibroblasts remained below $2.0 \%$. These results were paralleled in DAN G cells, with untransfected or mock transfected controls reaching only $4.8 \%$ and $5.1 \%$ apoptosis after 120 hours, respectively, and all bcl- 2 specific siRNAs inducing significant levels of cell death even at $10 \mathrm{nM}$, reaching $18.5 \%, 12.3 \%, 11.9 \%, 27.9 \%$, and $15.8 \%$, respectively (fig 2D).
Transfection of bcl-2 specific siRNA reduces pancreatic carcinoma cell numbers

All bcl-2 specific siRNA sequences reduced the relative cell number of YAP C pancreatic carcinoma cells (fig 3A). This effect was most pronounced for bcl3, bcl5, and bclll (up to more than $70 \%$ after 120 hours), while bcll and bcl 8 reduced cell proliferation by more than $50 \%$. Reduced cell viability was detectable as early as 24 hours after transfection. In fibroblasts, cell viability was not significantly altered after transfecting either unspecific control siRNAs or bcl-2 specific siRNA sequences (not shown). Cell number remained stable in both cell types over this time course for mock transfected cells and was reduced slightly, but not significantly, after transfection of control siRNAs 1 and 2 . The number of viable cells was slightly increased after transfection with control siRNA 3 (fig 3B). In contrast with YAP C, bcll did not reduce cell numbers in DAN G at $10 \mathrm{nM}$ after 120 hours (103.2\%), while the other bcl-2 specific siRNAs caused a reduction in viable tumour cells, reaching $86.7 \%, 62.5 \%, 54.6 \%$, and $47.0 \%$, respectively, after 120 hours (fig 3C).

\section{$\mathrm{Bcl}-2$ specific siRNA leads to rapid downregulation of the corresponding mRNA}

Quantitative real time PCR revealed spontaneous decrease in bcl-2 mRNA levels in control or mock transfected cells over the time course of 120 hours while steady state levels of the housekeeping gene $\beta_{2}$-microglobulin or the proapoptotic gene bax remained relatively stable (fig 4A, B), in accordance with cellular senescence during the time of the experiment. ${ }^{41}$ Transfection of bcl-2 specific siRNA led to a rapid but variable decrease in bcl-2 mRNA levels, with suppression persisting up to 120 hours. Here, bcl 8 was most effective,
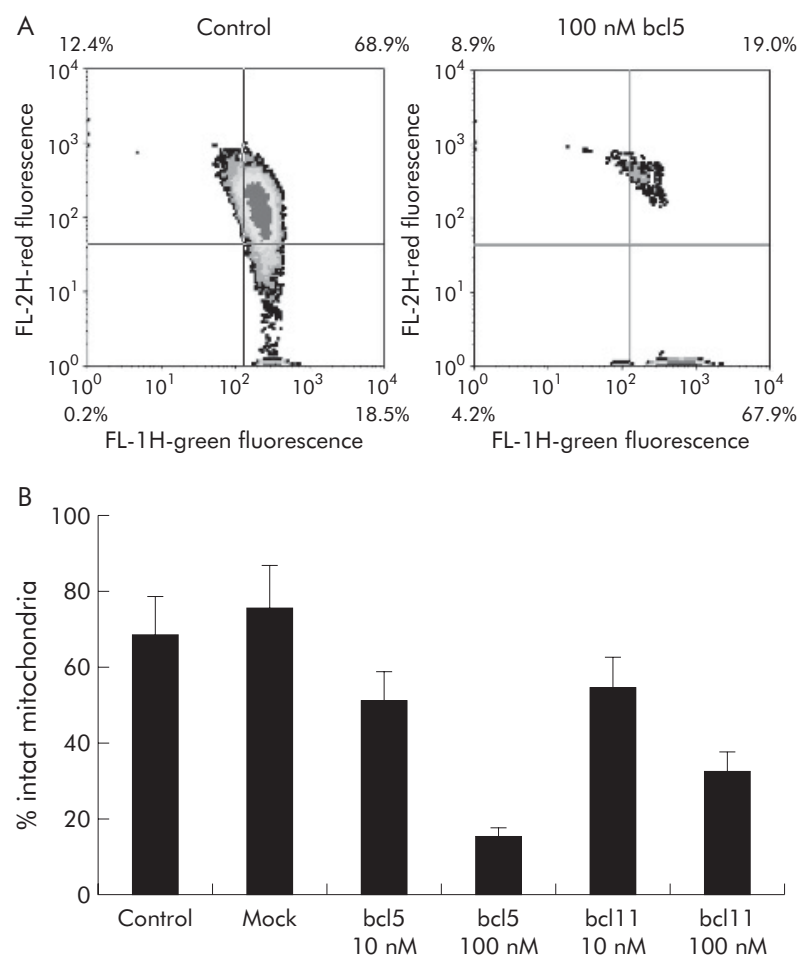

Figure 6 Loss of mitochondrial membrane integrity after bcl-2-short interfering RNA (siRNA) transfection. (A) Representative density plots of fluorescence detector $\mathrm{FL} 1-\mathrm{H}$ (green fluorescence, breakdown of $\Delta \Psi_{\mathrm{m}}$ ) versus FL2-H (red fluorescence, intact $\Delta \Psi_{\mathrm{m}}$ ), depicting all acquired events of untreated YAP C cells (left) or 120 hours after transfection with $100 \mathrm{nM}$ bcl5 (right). (B) Means (SEM) of three independent experiments. All bcl-2 specific siRNAs caused a rapid decrease in $\Delta \Psi_{m}(p<0.05)$ while no significant change was observed for mock transfected cells. 
while for bcl3 and bclll time and concentration dependent effects were observed. The proapoptotic counterpart of bcl-2, bax, remained stable in all experiments and showed an increase after transfection of bcl3 and bclll. Thus, on the mRNA level, the bax/bcl-2 ratio was shifted towards apoptosis induction.

\section{Expression of bcl-2 protein is diminished after transfection of bcl-2 specific siRNA}

FACS analysis revealed a significant reduction in bcl-2 protein levels after transfection of bcl5 or bclll in a time and dose dependent manner in YAP C cells (fig 5). Untreated controls and mock transfected cells showed high and stable levels of bcl-2 staining, even after 120 hours $(>70 \%$ of all detected events), while both bcl-2 specific siRNAs at $100 \mathrm{nM}$ reduced bcl-2-FITC signals to $24.3 \%$ (bcl5) or $40.9 \%$ (bcll1). A minor but significant reduction in bcl-2 protein levels was observed after transfection of $10 \mathrm{nM}$ bcl5 but not of bclll $(\mathrm{p}<0.05)$.

\section{Downregulation of bcl-2 disturbs mitochondrial membrane potential}

Paralleling the reduced expression of bcl-2 protein, the percentage of cells showing red fluorescence (that is, intact mitochondria) decreased compared with untreated or mock transfected cells (fig 6). With $10 \mathrm{nM}$ of bcl5 or bcl11, JC-1 red fluorescence was reduced to $51 \%$ and $54.5 \%$, respectively, after 120 hours, and was further reduced after transfection of $100 \mathrm{nM}$ siRNA ( $15.1 \%$ and $32.5 \%$, respectively). Red fluorescence correlated closely with levels of bcl-2 protein, as determined by flow cytometry $\left(r^{2}=0.9655\right)$. These findings indicate that bcl-2 is involved in maintaining mitochondrial membrane integrity and preventing induction of apoptosis.

\section{siRNA rapidly distributes in vivo and is eliminated via the kidney and liver}

Pharmacokinetic data using radioactively labelled siRNA were collected in male NMRI-mice. Ten minutes after a single bolus injection into the tail vein, radioactivity was
$H \& E$
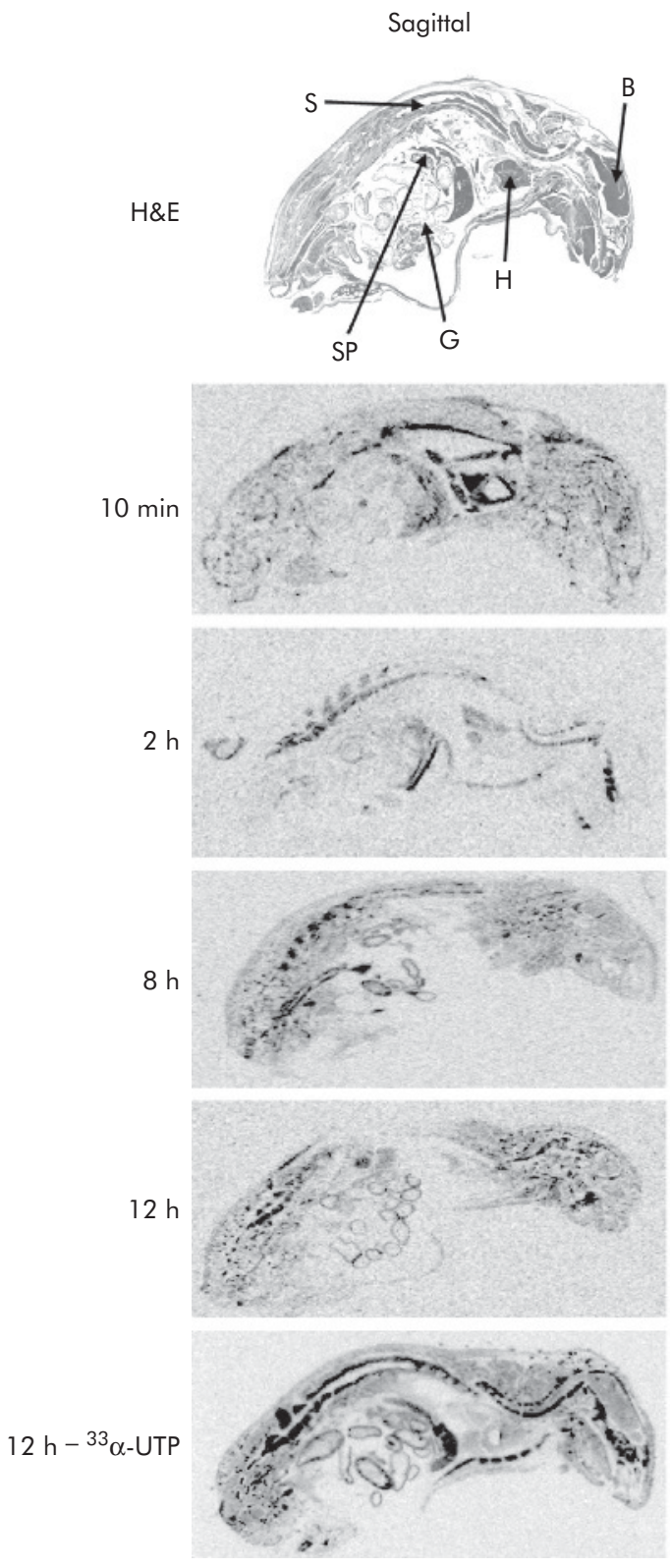

Para-sagittal right
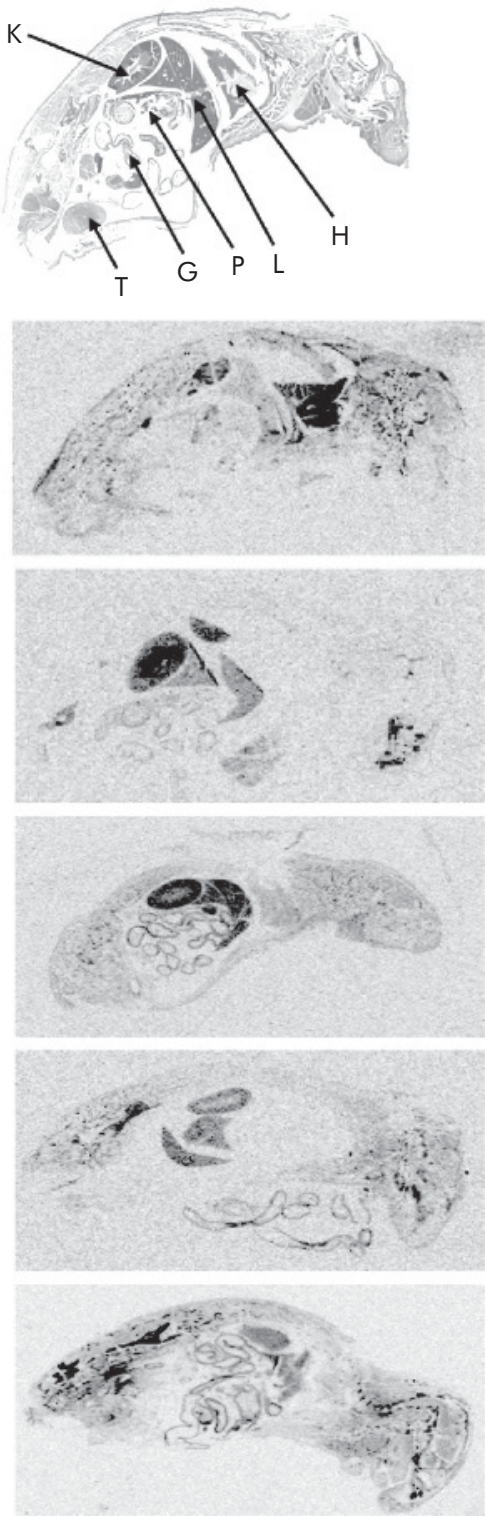

Figure 7 Distribution of ${ }^{33}$ P-labelled short interfering RNA (siRNA) in vivo. Representative phosphoimager analyses of sagittal (left column) and para-sagittal (right column) sections of animals sacrificed 10 minutes, and 2 , 8 , and 12 hours after intravenous bolus injection of labelled siRNA. Haematoxylin-eosin stainings of whole body sections are shown in the top row. Organs indicated by arrows are brain (B), gut (G), heart/thoracic haematoma $(\mathrm{H})$, kidney $(\mathrm{K})$, liver $(\mathrm{L})$, pancreas $(\mathrm{P})$, spine (S), spleen (SP), and testis (T). Bottom row shows representative sections of animals receiving pure ${ }^{33} \alpha$-UTP without nucleic acid as a control, sacrificed 12 hours after tail vein injection. Here, signals were more prominent in osseous tissues while in the siRNA treated animals, rapid redistribution from blood to kidney to liver and gut was visible. 
A
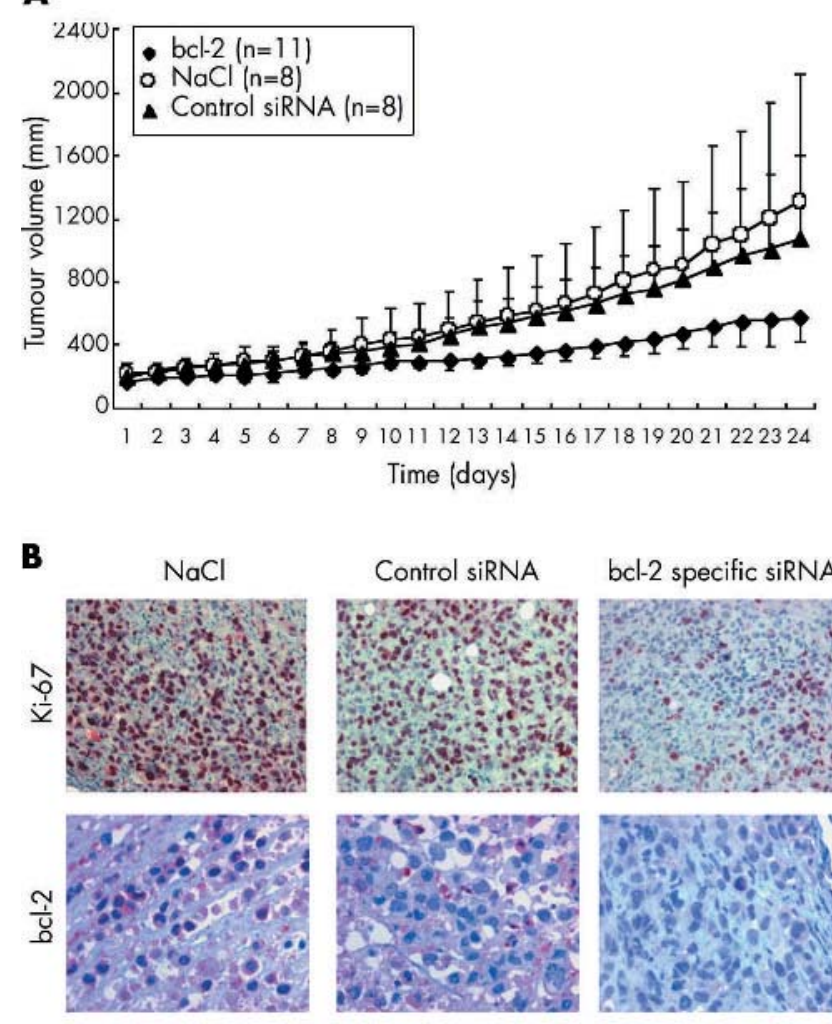

Control siRNA
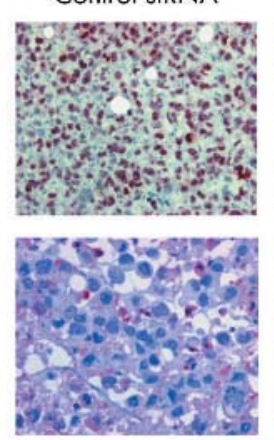

bcl-2 specific siRNA
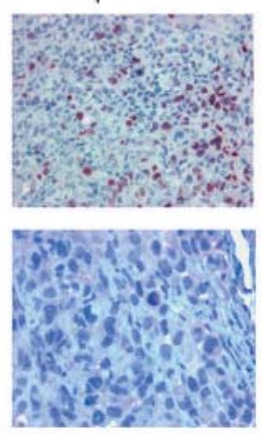

C

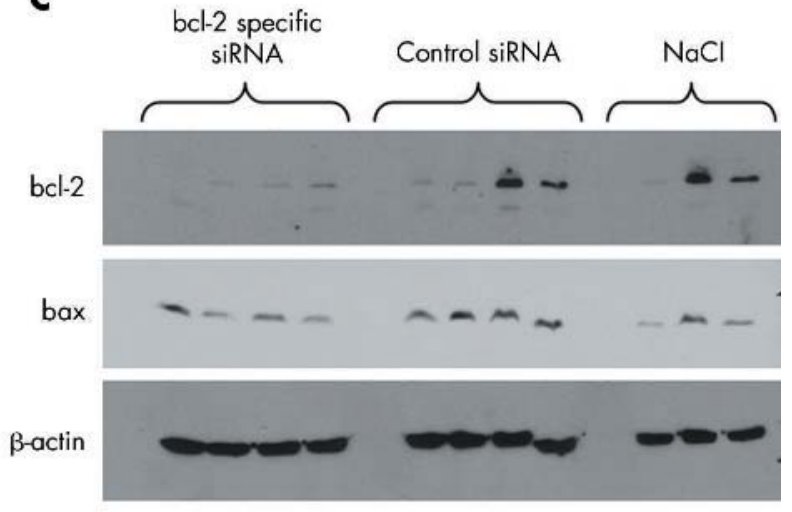

D

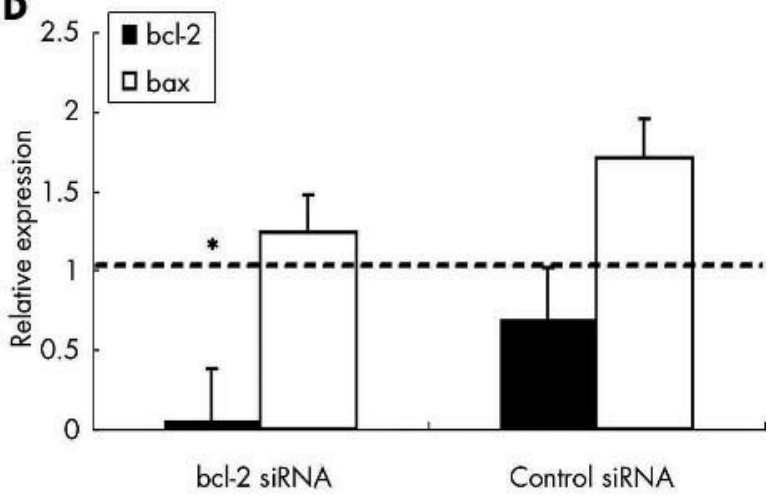

Figure 8 Growth inhibition of pancreatic cancer xenografts in nude mice by bcl-2 specific short interfering RNAs (siRNAs). (A) Size of subcutaneous pancreatic carcinoma xenografts in NMRI mice was determined by daily measurement with a standardised calliper square. Data represent mean (SD) tumour volume from animals treated with daily intraperitoneal injections of $200 \mu \mathrm{g} / \mathrm{kg}$ bcl-2 specific siRNA bcl5, control siRNA 1, or vehicle (physiological saline, $\mathrm{NaCl}$ ), beginning at day 1. (B) Immunohistochemical analysis of formalin fixed paraffin embedded tumour specimens revealed decreased expression of $\mathrm{Ki}-67$ in animals treated with siRNA against bcl-2 but not in control mice. Expression of bcl- 2 was decreased by approximately $56 \%$ in animals treated with siRNA against the target gene versus physiological saline controls ( $\mathrm{NaCl}$ ). (C) Western blot analysis of xenograft samples revealed specific downregulation of bcl-2 protein in all animals treated with bcl5, in two of four animals treated with control siRNA 1 , and in one of three mice from the $\mathrm{NaCl}$ group. Proapoptotic bax was detected in all samples; $\beta$-actin served as a loading control. (D) Semiquantification of western blot results. Mean (SEM) densitometry values per group relative to $\mathrm{NaCl}$ treated animals (broken line). ${ }^{*} \mathrm{p}<0.05$ versus $\mathrm{NaCl}$ treated animals.

quickly distributed by blood flow, showing intense signals in the heart and the retrocardial thoracic haematoma resulting from heart puncture (fig 7). Radioactivity was then redistributed to the kidney (two hours) and accumulated finally in the liver and gut wall (eight and 12 hours). In contrast, ${ }^{33} \alpha$-UTP alone showed signals predominantly in osseous tissues such as spine, skull, or the thoracic wall (fig 8, bottom row). These data indicate that a major proportion of siRNA is quickly excreted via the kidneys but is also metabolised and eliminated by the liver. While pancreata were clearly identified in haematoxylin-eosin stainings, unequivocal identification was not possible in phosphoimager analyses due to limitations in optical resolution. Overall, tissue distribution was homogenous, indicating that several target tissues can be reached with nude siRNA.

\section{Bcl-2 specific siRNA delays growth of pancreatic cancer xenografts in vivo}

To assess the efficacy of siRNA mediated gene silencing in vivo, mice ( $\mathrm{n}=1 \mathrm{l}$ for bcl-2, $\mathrm{n}=8$ for controls) bearing human pancreatic carcinoma xenografts were treated intraperitoneally with daily injections of either bcl5, control siRNA 1 , or physiological saline. All mice survived the 24 days of treatment without any signs of organ toxicity, as shown by histological analysis (for example, no haematopoietic arrest in the bone marrow, no hepatic or kidney necrosis). No significant weight loss was observed in treated or untreated animals. Minor signs of fibrinous peritonitis were observed in all groups due to daily intraperitoneal injections. Mean relative tumour volume in the bcl5 group was $579.1 \mathrm{~mm}^{3}$ compared with $1078.3 \mathrm{~mm}^{3}$ in the control siRNA group and $1307.2 \mathrm{~mm}^{3}$ in the saline control group, representing a $56 \%$ reduction in tumour volume in mice treated with bcl-2 specific siRNA versus $\mathrm{NaCl}$ (fig 8A). Reduced tumour volumes were matched to decreased tumour cell proliferation, as demonstrated by immunohistological staining for Ki-67. In the bcl5 group, only $19.3 \%$ of tumour cells showed positive staining for Ki-67 $(\mathrm{p}<0.05)$ compared with $31.7 \%$ in animals receiving control siRNA or $43.4 \%$ in animals that received physiological saline (fig 8B, top row). Expression of bcl-2 (fig 8B, bottom row) was only decreased in animals treated with siRNA against bcl-2 (3.7\% positive cells) but was highly expressed in animals that received $\mathrm{NaCl}$ solution or control siRNA $(75.0 \%$ and $61.5 \%$, respectively). These results indicate a high target specificity of RNAi in vivo. Semiquantitative western blotting from snap frozen 
xenograft specimens revealed specific downregulation of bcl-2 in three of four of the bcl5 treated animals while proapoptotic bax and the housekeeping protein $\beta$-actin remained unchanged (fig 8C). However, as yet unidentified factors may contribute to decreased tumour cell proliferation also. Thus in animals treated with control siRNA or with physiological saline, two of four also showed loss of bcl-2 whereas in others expression of the target gene remained elevated, indicating different endogenous expression of bcl-2 due to clonal expansion of low or high expressing tumour cells. Overall densitometric analysis showed a reduction in bcl-2 expression in the bcl5 treated group to a mean of $6.0 \%$ of expression in the $\mathrm{NaCl}$ group $(\mathrm{p}<0.05$, fig $8 \mathrm{D})$. In the control group, bcl-2 expression reached $70.0 \%$ of the saline control. Proapoptotic bax remained stable at a mean of $124 \%$ (bcl5) and $170 \%$ (control siRNA), shifting the bax/bcl-2 ratio to 20.7 in animals treated with bcl-2 specific siRNA compared with 2.5 in $\mathrm{NaCl}$ controls.

\section{DISCUSSION}

Efficient and well tolerated therapy for pancreatic cancer is urgently needed. Specific downregulation of genes that prevent apoptosis or chemotherapy resistance by RNAi is a promising treatment approach. Here, we have shown that siRNA molecules specifically targeting antiapoptotic bcl-2 lead to enhanced apoptosis and suppressed cell proliferation of pancreatic carcinoma in vitro and in vivo. Enhanced degradation of bcl-2 mRNA and protein was specific for the five bcl-2-siRNAs used, as several control siRNAs did not induce similar effects in pancreatic carcinoma cells while foreskin fibroblasts (used as control cells) remained largely unaffected.

Downregulation of bcl-2 by conventional antisense oligonucleotides has been shown to enhance apoptosis and chemotherapy sensitivity in a variety of human malignancies. $^{20214243}$ The bcl-2 family consists of proapoptotic (for example, bax) and antiapoptotic (for example, bcl-2 or bcl- $x_{\mathrm{L}}$ ) members. While the exact mechanisms still remain elusive, the rheostat model suggests that the balance of pro and antiapoptotic bcl-2 proteins decides cell fate at the mitochondrial level. ${ }^{44}$ Downregulation of bcl-2 disturbs mitochondrial membranes leading to a breakdown of the mitochondrial membrane potential $\Delta \Psi_{\mathrm{m}}$ and subsequent release of cytochrome $c$ from the mitochondrial intermembrane space which then activates the apoptosome and triggers the caspase cascade. ${ }^{44-46}$ Accordingly, we observed a breakdown of $\Delta \Psi_{\mathrm{m}}$ after transfection of bcl-2 specific siRNAs in YAP $C$ cells but not after transfecting control siRNAs, as evidenced by FACS analysis. JC-1 staining of $\Delta \Psi_{\mathrm{m}}$ correlated with protein levels of bcl-2, indicating specific silencing by corresponding siRNAs. Importantly, applying bcl-2 specific siRNA in vivo leads to tumour reduction, accompanied by specific downregulation of bcl-2 mRNA and protein, as shown by RT-PCR, western blotting, and immunohistochemistry.

Furthermore, in accordance with cell culture results, cell proliferation (as shown by Ki-67 immunohistochemistry) was reduced in vivo. However, unspecific control siRNA also caused a slight decrease in Ki-67 staining, while proliferation was unaffected in the $\mathrm{NaCl}$ group. We also found low levels of bcl-2 expression in some control animals that did not receive anti-bcl-2 siRNA, as we did not pool protein extracts from all animals of one experimental group to perform semiquantitative western blotting. This is explained by expansion of different pancreatic cancer cell clones, some of which express bcl-2 only at low levels, in the experimental tumours (data not shown). However, overall, bcl-2 expression was downregulated significantly in the anti-bcl-2 siRNA treated group compared with the control groups.
Furthermore, apart from the highly target specific effects of siRNAs, other activities appear to contribute to the observed growth inhibition of pancreatic cancer xenografts in vivo.

While it was shown that only long dsRNA molecules can trigger an interferon response and upregulate interferon dependent genes (for example, Janus family tyrosine kinase, JAK, and signal transducers and activators of transcription, Stats), recent reports have demonstrated that siRNAs can also induce changes in genes unrelated to the targeted sequence (for example, upregulation of p21 and p53 $3^{47-49}$ which might induce bystander effects in untransfected cells). RNAi is a highly conserved biological response mechanism against genomic contamination by dsRNA, such as by viral infection, and several dsRNA binding proteins, such as wig-l, have been identified recently. ${ }^{50}$ These proteins have been shown to be involved in p53 signalling, ${ }^{51}$ inducing growth arrest for example, ${ }^{52}$ and therefore likely contributing to the observed growth inhibition after transfecting unspecific siRNA in vitro and in vivo. These factors, as well as clonal expansion of untransfected cells, may be responsible for the observed discrepancy between cell number and apoptosis rate.

Unpredictable interactions, toxicity, and variability in silencing different target genes, coupled with weak in vivo stability, have been major drawbacks for the routine administration of antisense oligonucleotides. This contrasts with the favourable in vivo stability of siRNA ${ }^{53}$ which was applied to numerous therapeutic genes in vitro and to mouse models in vivo. ${ }^{54}{ }^{57}$ Variant silencing potency of siRNAs may be due to different transfection efficacies in several experimental settings. Importantly, it has been commonly observed that some siRNAs derived from and targeted to the same mRNA possess pronounced silencing activity, while others are barely active. We also observed variable proapoptotic effects of our five siRNAs targeting the bcl-2 gene but also of control siRNA 1. Our siRNAs varied in length for the paired duplex ( 21 or $22 \mathrm{nt}$ ) and the target region in the bcl-2 mRNA. Recent publications showed that the rational design of siRNAs can enhance their silencing activities. ${ }^{58-60}$ Thus separation of the siRNA duplex into sense and antisense strands is mediated by an ATP dependent helicase. Dependent on which end of the duplex is more accessible for the enzyme, either the desired antisense strand (unwinding from the 3'-end of the sense strand) or the unwanted sense strand (unwinding from the $5^{\prime}$-end of the sensestrand) is predominantly incorporated into RISC. When the sense strand is incorporated, no cleavage of the targeted mRNA is observed, which explains the ineffectiveness of some siRNAs. Strand separation from the 3'-end can be facilitated by selecting for A/U base pairs in positions 15-19, as has been done for all of our bcl-2 specific siRNAs (table 1). Further improvement in siRNA design (for example, by inserting mismatches in the nt 15-19 region of the duplex or chemical variations to the phosphate backbone) might further enhance strand separation and lead to increased silencing activity. ${ }^{55} 56$

siRNAs have been used to suppress expression of reporter genes under experimental conditions in mice. ${ }^{32-34} 57$ Ours is the first report on silencing of an endogenous target gene in a solid cancer after systemic administration of unmodified siRNAs in vivo, investigating the therapeutic utility of siRNA in the treatment of these disease entities. Furthermore, we showed that siRNAs are homogenously distributed in all organs of adult mice after intraperitoneal administration followed by renal clearance and a second hepatic elimination phase. Chemical modification of siRNA duplexes can further improve tissue targeting (for example, by tagging to RGD peptides for increased cellular uptake) and in vivo stability. ${ }^{53} 61$ 
More studies are needed to assess the pharmacokinetics and improve tissue specific targeting of certain genes with siRNA. Enhancing cleavage of bcl-2 mRNA by siRNA may contribute to the treatment of pancreatic cancer by improving chemotherapy sensitivity of this otherwise resistant carcinoma.

\section{ACKNOWLEDGEMENTS}

This work was supported by grants from the German Cancer Aid (102112-Ocl), the FUTUR-Programme of the State of Bavaria (project No. 263), and the ELAN-Programme of the Faculty of Medicine University of Erlangen-Nuernberg (project 02.08.08.2).

We are indebted to Sandra Leitner, Catherina Kühl, and Gisela Weber for excellent technical assistance, and to Gabriele Krumholz for support in animal care and animal experiments. Professor Torsten Kuwert and Dr Olaf Prante, Department of Nuclear Medicine, are acknowledged for support in radioactive animal experiments. We thank Ribopharma AG, Kulmbach, Germany, for providing siRNAs and Dr Anke Geick, Ribopharma AG, for performing western blotting from in vivo material. We are grateful to Dr Hans-Peter Vornlocher, Ribopharma AG, for intense and fruitful discussions.

\section{Authors' affiliations}

M Ocker*, M Lueders, S Zopf, M Ganslmayer, E G Hahn, C Herold, Department of Medicine I, Friedrich-Alexander-University ErlangenNuernberg, Erlangen, Germany

D Neureiter*, Department of Pathology, Friedrich-Alexander-University Erlangen-Nuernberg, Erlangen, Germany, and Institute of Pathology, Paracelsus Medical Private University, Salzburger Landeskliniken, Salzburg, Austria

D Schuppan, Department of Gastroenterology and Hepatology, Beth Israel Deaconess Medical Center, Harvard Medical School, Boston, MA, USA, and Department of Medicine I, Friedrich-Alexander-University Erlangen-Nuernberg, Erlangen, Germany

${ }^{*} M$ Ocker and D Neureiter contributed equally to this work Conflict of interest: None declared.

\section{REFERENCES}

1 Keighley MRB. Gastrointestinal cancers in Europe. Aliment Pharmacol Ther 2003; 18:7-30

2 DiMagno E, Reber HA, Tempero MA. AGA technical review on the epidemiology, diagnosis, and treatment of pancreatic ductal adenocarcinoma. Gastroenterology 1999;117:1464-84.

3 Simon B, Printz H. Epidemiological trends in pancreatic neoplasias. Dig Dis $2001 ; 19: 6-14$.

4 Raraty MGT, Magee CJ, Ghaneh P, et al. New techniques and agents in the adjuvant therapy of pancreatic cancer. Acta Oncol 2002;41:582-95.

5 Nitecki SS, Sarr MG, Colby TV, et al. Long-term survival after resection for ductal adenocarcinoma of the pancreas: is it really improving? Ann Surg 1994;221:59-66.

6 Bardeesy N, Sharpless NE, DePinho RA, et al. The genetics of pancreatic adenocarcinoma: a roadmap for a mouse model. Semin Cancer Biol $2001 ; 11: 201-18$.

7 Almoguera C, Shibata D, Forrester K, et al. Most carcinomas of the exocrine pancreas contain mutant c-Kras genes. Cell 1998;53:549-59.

8 Hrubran RH, van Mansfeld AOM, Offerhaus GJA, et al. K-ras oncogene activation in adenocarcinomas of the human pancreas: a study of 82 carcinomas using a combination of mutant-rich PCR analysis and allele oligonucleotide hybridization. Am J Pathol 1993; 143:545-54.

9 Goldstein AM, Fraser MC, Struewing JP, et al. Increased risk of pancreatic cancer in melanoma-prone kindreds with pl6INK4 mutations. N Engl J Med 1995; 333:970-4.

10 Simon B, Weinel R, Hohne MW, et al. Frequent alterations of the tumor suppressor genes p53 and DCC in human pancreatic carcinoma. Gastroenterology 1994;106:1645-51.

11 Campani D, Esposito I, Boggi U, et al. Bcl-2 expression in pancreas development and pancreatic cancer progression. J Pathol $2001 ; 194: 444-50$.

12 Miyamoto $Y$, Hosotani R, Wada $M$, et al. Immunohistochemical analysis of $\mathrm{Bcl}-2, \mathrm{Bax}, \mathrm{Bcl}-\mathrm{x}$, and $\mathrm{Mcl}-1$ expression in pancreatic cancers. Oncology 1999;56:73-82.

13 Hockenbery DM, Nunez G, Milliman C, et al. Bcl-2 is an inner mitochondrial membrane protein that blocks programmed cell death. Nature 1990;348:334-6.

14 Boise LH, Gonzalez-Garcia M, Postema CE, et al. Bcl-xL, a bcl-2 related gene that functions as a dominant regulator of apoptotic cell death. Cell 1993;74:597-608.
15 Chittenden T, Harrington EA, O'Conner R, et al. Induction of apoptosis by the bcl-2 homologue Bak. Nature 1995;374:733-6.

16 Cory S, Adams JM. The bcl 2 family: regulators of the cellular life-or-death switch. Nature Rev Cancer 2002;2:647-56.

17 Cotter FE, Waters J, Cunningham D. Human bcl-2 antisense therapy for lymphomas. Biochim Biophys Acta 1999;1489:97-106.

18 Pepper C, Thomas A, Hoy T, et al. Antisense-mediated suppression of bcl-2 highlights its pivotal role in failed apoptosis in B-cell chronic lymphocytic leukaemia. Br J Haematol 1999;107:611-15.

19 Chi KN, Wallis AE, Lee $\mathrm{CH}$, et al. Effects of bcl-2 modulation with G3139 antisense oligonucleotide on human breast cancer cells are independent of inherent bcl-2 protein expression. Breast Cancer Res Treat 2000;63:199-212.

20 Jansen B, Wacheck V, Heere-Ress E, et al. Chemosensitisation of malignant melanoma by bcl2 antisense therapy. Lancet 2000;356:1728-33.

21 Wacheck V, Heere-Ress E, Halaschek-Wiener J, et al. Bcl-2 antisense oligonucleotides chemosensitize human gastric cancer in a SCID mouse xenotransplantation model. J Mol Med 2001;79:587-93.

22 Lebedeva I, Stein CA. Antisense oligonucleotides: promises and reality. Annu Rev Pharmacol Toxicol 2001;41:403-19.

23 Stahel RA, Zangemeister-Wittke U. Antisense oligonucleotides for cancer therapy-an overview. Lung Cancer 2003:41:S81-8.

24 Rudin CM, Otterson GA, Mauer AM, et al. A pilot trial of G3139, a bcl-2 antisense oligonucleotide, and paclitaxel in patients with chemorefractory small-cell lung cancer. Ann Oncol 2002;13:539-45.

25 Elbashir SM, Harborth J, Lendeckel W, et al. Duplexes of 21-nucleotide RNAs mediate RNA interference in cultured mammalian cells. Nature 2001;411:494-8

26 Elbashir SM, Lendeckel W, Tuschl T. RNA interference is mediated by 21 - and 22-nucleotide RNAs. Genes Dev 2001;15:188-200.

27 Fire A, Xu S, Montgomery MK, et al. Potent and specific genetic interference by double-stranded RNA in Caenorhabditis elegans. Nature 1998;391:806-11.

28 Bernstein E, Caudy AA, Hammond SM, et al. Role for a bidentate ribonuclease in the initiation step of RNA interference. Nature 2001;409:363-6.

29 Zamore PD, Tuschl T, Sharp PA, et al. RNAi: double-stranded RNA directs the ATP-dependent cleavage of mRNA at 21 to 23 nucleotide intervals. Cell 2000;101:25-33.

30 Hannon GJ. RNA interference. Nature 2002;418:244-51

31 Martinez J, Patkaniowska A, Urlaub H, et al. Single-stranded antisense siRNAs guide target RNA cleavage in RNAi. Cell 2002; 1 10:563-74.

32 McCaffrey AP, Meuse L, Pham T, et al. RNA interference in adult mice. Nature 2002;418:38-9.

33 Song E, Lee SK, Wang J, et al. RNA interference targeting Fas protects mice from fulminant hepatitis. Nat Med 2003;9:347-51

34 Sorensen DR, Leirdal M, Sioud M. Gene silencing by systemic delivery of synthetic siRNAs in adult mice. J Mol Biol 2003:327:761-6.

35 Wilson JA, Jayasena S, Khvorova A, et al. RNA interference blocks gene expression and RNA synthesis from hepatitis $C$ replicons propagated in human liver cells. Proc Natl Acad Sci U S A 2003;100:2783-8.

36 Capodici J, Kariko K, Weissman D. Inhibition of HIV-1 infection by small interfering RNA-mediated RNA interference. J Immunol 2002;169:5196-201

37 Scherr M, Battmer K, Winkler T, et al. Specific inhibition of bcr-abl gene expression by small interfering RNA. Blood 2002;101:1566-9.

38 Ocker M, Herold C, Ganslmayer M, et al. The synthetic retinoid adapalene inhibits proliferation and induces apoptosis in colorectal cancer cells in vitro. Int J Cancer 2003; 107:453-9.

39 Lohwasser S, Ernst H, Hahn EG, et al. Morphological changes in human colon carcinoma after chemotherapy with 5 -fluorouracil-a study in the nude mouse model. Z Gastroenterol 1997;35:319-26.

40 Cattoretti G, Becker MH, Key G, et al. Monoclonal antibodies against recombinant parts of $\mathrm{Ki}-67$ antigen (MIB 1 and MIB 3) detect proliferating cells in microwave-processed formalin-fixed paraffin sections. J Pathol 1992;168:357-63

41 Sasaki M, Kumazaki T, Takano H, et al. Senescent cells are resistant to death despite low bcl-2 level. Mech Ageing Dev 2001;122:1695-706.

42 Waters SJ, Webb A, Cunningham D, et al. Phase I clinical and pharmacokinetic study of bcl-2 antisense oligonucleotide therapy in patients with non-Hodgkin's lymphoma. J Clin Oncol 2000;18:1812-23.

43 Zangemeister-Wittke U. Antisense to apoptosis inhibitors facilitate chemotherapy and TRAIL-induced death signaling. Ann NY Acad Sci 2003;1002:90-4.

44 Borner C. The bcl-2 protein family: sensors and checkpoints for life-or-death decisions. Mol Immunol 2003;39:615-47.

45 Hengartner MO. The biochemistry of apoptosis. Nature 2000;407:770-6.

46 Kuwana T, Mackey MR, Perkins G, et al. Bid, bax, and lipis cooperate to form supramolecular openings in the outer mitochondrial membrane. Cell 2002;111:331-42.

47 Scacheri PC, Rozenblatt-Rosen O, Caplen NJ, et al. Short interfering RNAs can induce unexpected and divergent changes in the levels of untargeted proteins in mammalian cells. Proc Natl Acad Sci U S A 2004;101:1892-7.

48 Sledz CA, Holko M, de Veer M, et al. Activation of the interferon system by short-interfering RNAs. Nat Cell Biol 2003;5:834-9.

49 Persengiev SP, Zhu X, Green MR. Nonspecific, concentration-dependent stimulation and repression of mammalian gene expression by small interfering RNAs (siRNAs). RNA 2004;10:12-18.

50 Fierro-Monti I, Mathews MB. Proteins binding to duplexed RNA: one motif, multiple functions. Trends Biochem Sci 2000;25:241-6. 
51 Hellborg F, Qian W, Mendez-Vidal C, et al. Human wig-1, a p53 target gene that encodes a growth inhibitory zinc finger protein. Oncogene $2001 ; 20: 5466-74$.

52 Méndez-Vidal C, Wilhelm MT, Hellborg F, et al. The p53-induced mouse zinc finger protein wig-1 binds double-stranded RNA with high affinity. Nucleic Acids Res 2002;30:1991-6.

53 Bertrand JR, Pottier M, Vekris A, et al. Comparison of antisense oligonucleotides and siRNAs in cell cultuire and in vivo. Biochem Biophys Res Com 2002;296:1000-4.

54 Yin JQ, Gao J, Shao R, et al. siRNA agents inhibit oncogene expression and attenuate human tumor cell growth. J Exp Ther Oncol 2003;3:194-204.

55 Harborth J, Elbashir SM, Vandenburgh K, et al. Sequence, chemical, and structural variation of small interfering RNAs and short hairpin RNAs and the effect on mammalian gene silencing. Antisense Nucleic Acid Drug Dev 2003;13:83-105.
56 Czauderna $F$, Fechtner $M$, Dames $S$, et al. Structural variations and stabilising modifications of synthetic siRNA in mammalian cells. Nucleic Acids Res 2003;31:2705-16

57 Zender L, Hütker S, Liedtke C, et al. Capase 8 small interfering RNA prevents acute liver failure in mice. Proc Natl Acad Sci U S A 2003:100:7797-802

58 Ui-Tei K, Naito Y, Takahashi F, et al. Guidelines for the selection of highly effective siRNA sequences for mammalian and chick RNA interference. Nucleic Acids Res 2004;32:936-48.

59 Reynolds A, Leake D, Boese $Q$, et al. Rational siRNA design for RNA interference. Nat Biotechnol 2004;22:326-30

60 Schwarz DS, Hutvagner G, Du T, et al. Asymmetry in the assembly of the RNAi enzyme complex. Cell 2003;115:199-208

61 Kurreck J. Antisense technologies: Improvement through novel chemica modifications. Eur J Biochem 2003;270:1628-44.

\section{EDITOR'S QUIZ: GI SNAPSHOT}

\section{Answer}

From question on page 1262

Gastroscopy showed a bulge at the posterior wall of the fundus. The computed tomography scan identified a homogeneous cystic lesion of the spleen, $6 \times 8 \mathrm{~cm}$ in diameter, of liquid density. Endoscopic ultrasound showed an anechoeic cyst with a thin wall and septas. She underwent splenectomy. At histology (fig 4), the cystic wall consisted of fibrous tissue covered with a non-keratinised squamous lining. The final diagnosis was epidermoid cyst.

Non-parasitic splenic cysts (NPSC) are uncommon. The first classifications were performed by Fowler ${ }^{1}$ and Martin. ${ }^{2}$ Morgenstern $^{3}$ proposed a new classification based on the gross appearance and type of cellular lining. Seventy five per cent of NPSC are pseudocysts with only fibrous tissue lining, with a history of trauma in most people. The remainder are true cysts with cellular lining, including epidermoid cysts, and are thought to be congenital. ${ }^{4}$ Non-operative treatment is recommended for small asymptomatic cysts.

\section{References}

1 Fowler RH. Non parasitic benign cystic tumors of the spleen. Int Abs Surg 1953;96:209-27.

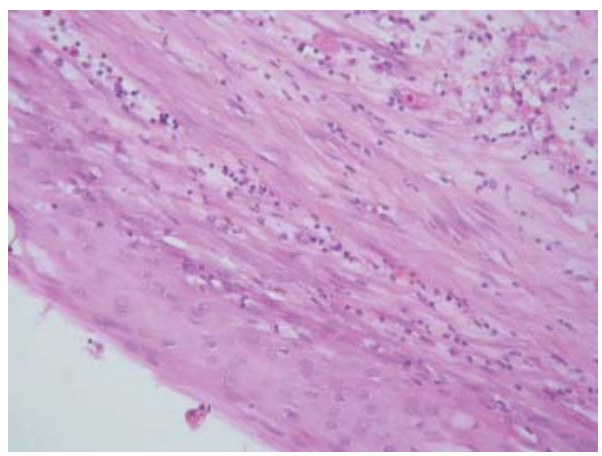

Figure 4 Histology of the spleen.

2 Martin JW. Congenital splenic cysts. Am J Surg 1958;96:302-8

3 Morgenstern L. Nonparasitic splenic cysts : pathogenesis, classification, and treatment. J Am Coll Surg 2002;194:306-14.

4 Robbins FG, Yellin AE, Lingua RW, et al. Splenic epidermoid cysts. Ann Surg 1978;187:231-5. 